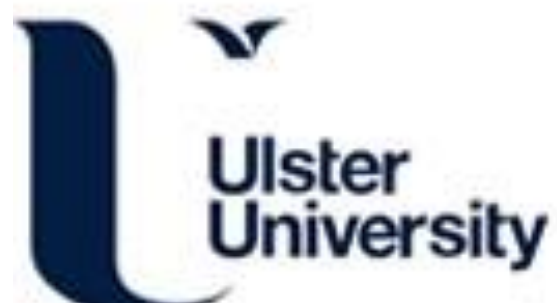

Effect of temporal frequency and contrast on peripheral grating resolution.

Anderson, R., Detkova, P., \& O'Brien, C. (1995). Effect of temporal frequency and contrast on peripheral grating resolution. Current Eye Research, 14, 1031-1033.

Link to publication record in Ulster University Research Portal

\section{Published in:}

Current Eye Research

Publication Status:

Published (in print/issue): 01/01/1995

\section{Document Version}

Publisher's PDF, also known as Version of record

\section{General rights}

Copyright for the publications made accessible via Ulster University's Research Portal is retained by the author(s) and / or other copyright owners and it is a condition of accessing these publications that users recognise and abide by the legal requirements associated with these rights.

\section{Take down policy}

The Research Portal is Ulster University's institutional repository that provides access to Ulster's research outputs. Every effort has been made to ensure that content in the Research Portal does not infringe any person's rights, or applicable UK laws. If you discover content in the Research Portal that you believe breaches copyright or violates any law, please contact pure-support@ulster.ac.uk. 


\title{
Effect of temporal frequency and contrast on peripheral grating
} resolution

\author{
R. S. Anderson, P. Detkova and C. O'Brien \\ University of Edinburgh, Department of Ophthalmology, Edinburgh, Scotland, UK
}

\begin{abstract}
We measured resolution at 10 degrees in the inferior temporal retina using horizontal and vertical gratings of different contrasts which modulated in time at temporal frequencies from 0 to $40 \mathrm{~Hz}$. Since peripheral grating resolution is directly related to the sampling density of retinal ganglion cells this allowed us to observe changes in responding ganglion cell density as the stimulus properties changed to selectively stimulate magnocellular pathway cells ( $M$ cells) instead of parvocellular pathway cells (P cells). At all contrasts there was no decline in resolution performance up to $10 \mathrm{~Hz}$, after which resolution deteriorated significantly, this effect being greater at lower contrasts. The predicted psychophysical resolution limit for $\mathrm{M}$ cells calculated from the anatomical data of Dacey indicates that resolution for high temporal frequency $(30 \mathrm{~Hz})$ or low contrast $(5 \%)$ stimuli is too good to be mediated by $M$ cells alone and there is still significant $P$ cell stimulation by these stimuli. Curr. Eye Res. 14: 1031-1033, 1995.
\end{abstract}

Key words: contrast; ganglion cells; peripheral acuity; temporal frequency

\section{Introduction}

For some time, visual acuity in peripheral vision has been directly related to ganglion cell density $(1,2,3)$ and the theory relating ganglion cell density and grating acuity in peripheral vision has become well developed. Thibos et al. (4) proposed that minimum angle of resolution (MAR) for a stationary grating in the periphery is equal to the spacing of retinal ganglion cells, in particular the beta class of cells which they assumed to constitute approximately $80 \%$ of all ganglion cells. Outside the fovea ganglion cell sampling density decreases very quickly $(4,5)$. Spatial frequencies higher than the resolution limit of the ganglion cell sampling array are imaged on the retina and this gives rise to observations of aliasing (6-9)

Correspondence: Dr Roger S. Anderson, University of Edinburgh, Department of Ophthalmology, Princess Alexandra Eye Pavilion, Chalmers Street, Edinburgh, Scotland, UK indicating that resolution is sampling limited in the peripheral retina. Building on the knowledge that peripheral resolution is sampling limited, Anderson et al. (10) demonstrated that peripheral ganglion cell density can be reliably estimated by measurements of grating acuity.

These previous measures of peripheral grating resolution have predominantly employed high contrast, stationary gratings. This kind of stimulus is believed to selectively stimulate the class of ganglion cells which project to the parvocellular layers of the lateral geniculate nucleus ( $P$ cells) displaying tonic responses to visual stimuli. The class of ganglion cells which project to the magnocellular layers of the lateral geniculate nucleus ( $M$ cells), however, display phasic responses to visual stimuli and are believed to be more sensitive to stimuli of high temporal frequency and low contrast. We extended previous methods further by measuring resolution acuity for peripheral viewing using gratings of different contrasts, that flickered at different temporal frequencies. We hypothesized that as temporal frequency increases and contrast decreases, the $\mathrm{P}$ cells should respond less and less and the $\mathrm{M}$ cells more and more. Also, since MAR is related to receptive field spacing we hypothesized that as resolution is decreasingly mediated by $P$ cells and increasing mediated by $M$ cells which are less numerous, resolution performance should decrease in proportion to the density of responding cells. The resolution results allow us to directly calculate the density of responding cells at each temporal frequency and may help decide which temporal frequencies best stimulate $\mathrm{M}$ cells.

\section{Materials and methods}

Stimuli were generated using a Visual Stimulus Generator VSG2/3 (Cambridge Research Systems) on an Eizo monitor. Stimuli consisted of 2.5 degree patches of sinewave gratings which had the same mean luminance as the surround.

Two subjects, both emmetropes, were used as observers. Subjects fixated a cross at $1.75 \mathrm{~m}$ in front with the right eye while gratings were presented on the monitor positioned at 10

Received on April 20, 1995; accepted on August 3, 1995

(C) Oxford University Press 
degrees in the superior nasal field (inferior temporal retina). The reason for using this oblique meridian is that acuity for horizontal and vertical gratings is similar unlike the horizontal meridian where acuity is higher for horizontal gratings, or the vertical meridian where acuity is higher for vertical gratings (11). This disparity in performance may have been a cue to deciding which orientation was presented.

The peripheral refractive error at 10 degrees eccentricity was determined using retinoscopy and found to be insignificant for both subjects. No corrective lenses were therefore used.

Resolution was measured in cycles/degree for stimuli of fixed contrast $(100,50,20,10$ or $5 \%)$ which flickered (sinusoidal phase reversal) at a fixed temporal frequency $(0,5,10,15$, 20,30 or $40 \mathrm{~Hz}$ ). For each session the temporal frequency and contrast of the stimulus was set and gratings were presented with orientation either horizontal or vertical in a random fashion. Eighty presentations were made in each session and threshold was determined by a two alternative forced choice (2AFC) reversal strategy where the subject was required to indicate the orientation of the grating by pressing one of two buttons. Three successive correct responses caused spatial frequency to be incremented by $10 \%$ for that stimulus and one incorrect response meant a decrement of $10 \%$ in spatial frequency at the next presentation of that stimulus. This gave, on average, 8 reversal values for each temporal frequency and threshold for each stimulus was calculated as the mean of the reversal values.

For a particular stimulus contrast we predicted that resolution performance would change with temporal frequency according to one of the three following hypotheses:

1) There is no change in resolution with increasing temporal frequency which would indicate that there is no loss of $\mathrm{P}$ cell function and transfer to $\mathrm{M}$ cell function.

2) There is a smooth and steady decrease in resolution with increasing temporal frequency indicating that $\mathrm{P}$ cells begin to 'drop out' as soon as the stimulus begins to flicker and continue to do so as temporal frequency increases.

3) There is no change in resolution up to a certain temporal frequency after which resolution declines smoothly and steadily. This would be expected if there is no decrease in the numbers of responding $P$ cells up to a critical temporal frequency after which they cease to respond in increasing numbers.

\section{Results}

Figure $1 \mathrm{~A}$ and $1 \mathrm{~B}$ are plots of temporal frequency versus threshold spatial frequency for different contrast stimuli for both subjects. The most obvious feature of the results is that for all contrasts there was no significant deterioration in resolution until temporal frequency went beyond $10 \mathrm{~Hz}$ after which performance declined steadily. This means that for all curves hypothesis 3 holds in that resolution remains unchanged up to a certain temporal frequency and then begins to deteriorate smoothly but significantly.

The decrease in resolution after $10 \mathrm{~Hz}$ is more pronounced at higher temporal frequencies and for stimuli of lower contrast. As temporal frequency increased from 0 to $40 \mathrm{~Hz}$, resolution declined by about a factor of 3 for $100 \%$ contrast and a factor of 4 at $30 \%$ contasts. For very low contasts the subjects found the task impossible at high spatial frequencies.

\section{Discussion}

Since grating resolution in the periphery is not limited by the optics of the eye in the same way as for foveal vision this means that we can obtain direct estimates of functional ganglion cell density (MAR $=$ spacing). Assuming a square array this would predict a responding ganglion cell density of $1880 \mathrm{GC} /$ $\mathrm{mm}^{2}$ for gratings of high contrast and temporal frequency at
A

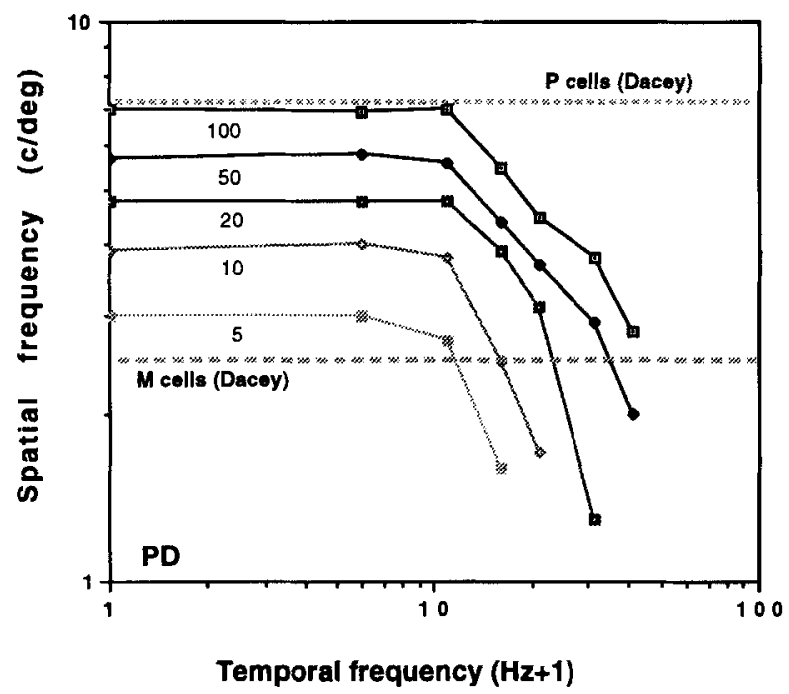

B

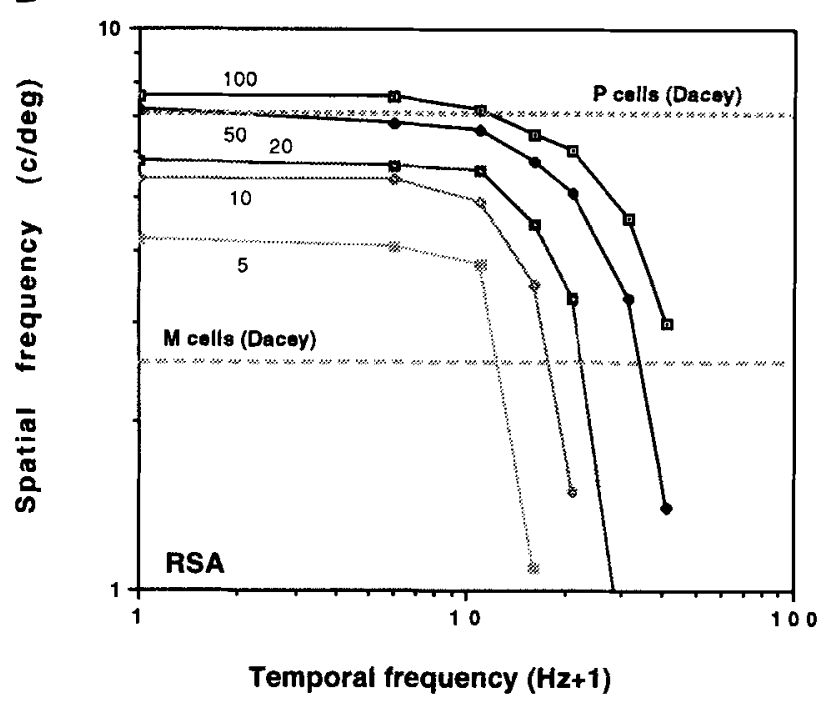

Figure 1. Plot of threshold spatial frequency for resolution vs stimulus temporal frequency for stimuli of different contrast. Subjects (A) PD and (B) RSA. 
or below $10 \mathrm{~Hz}$. The foregoing results, therefore, provide information on the density of responding ganglion cells at different temporal frequencies and contrasts in a specific retinal location.

The results indicate that there is little or no decline in resolution until around $10 \mathrm{~Hz}$ for stimuli of different contasts. Hypothesis 3 holds in this case and this implies that $\mathrm{P}$ cells respond robustly and without loss of numbers until this temporal frequency. It should be noted, however, that although there is an obvious decline in resolution after $10 \mathrm{~Hz}$, this decline is generally smooth (except perhaps for very low contrast stimuli). This indicates that any loss of $P$ cell function is gradual and there is no obvious point at which resolution suddenly changes from being solely $\mathrm{P}$ cell to solely $\mathrm{M}$ cell mediated. This suggests that there is considerable overlap in their function.

To illustrate this point further we have drawn two dashed lines on the graphs. The upper line represents the predicted psychophysical resolution limit (Nyquist limit) calculated by Dacey (12) from his anatomical data on the densities of midget ganglion cells which correspond to $\mathrm{P}$ cells. For both subjects this line falls extremely close to the points representing the resolution limit for high contrast low temporal frequency stimuli, which we know is mediated predominatly by $\mathrm{P}$ cells. Our psychophysical data therefore show good agreement with the anatomical data of Dacey.

The lower dashed line represents the predicted Nyquist limit for $M$ cells which Dacey claimed accounted for less than $10 \%$ of the total ganglion cell population at this eccentricity (although it is higher at more peripheral eccentricities). This Nyquist limit assumes an $\mathrm{M}$ cell population of $10 \%$ of the total population at this eccentricity and is probably, therefore, an optimistic estimate. It is obvious that the vast majority of the threshold points on these curves lie above this limit meaning that resolution performance for all these stimuli is too high to be mediated by $\mathrm{M}$ cells alone. This means that $\mathrm{P}$ cells continue to respond in significant numbers even for stimuli of low contrast $(10 \%)$ or high temporal frequency $(30 \mathrm{~Hz})$. It should not be assumed, however, that the data points below the $\mathrm{M}$ cell Nyquist line represent resolution that is mediated solely by $\mathrm{M}$ cells. Although the $\mathrm{M}$ cell population is theoretically capable of this kind of resolution performance, it is still possible (or even probable) that some $\mathrm{P}$ cells continue to respond to very low contrast, high temporal frequency stimuli. Conversely, it is possible that some $M$ cells are involved in resolving the higher contrast, lower temporal frequency stimuli represented above the $M$ cell Nyquist line, although behavioural lesion studies in monkey indicate that $\mathbf{M}$ cells contribute little until high temporal frequencies and low contrasts $(13,14)$. Performance that is purely $M$ cell mediated is probably not reached until well below the $\mathrm{M}$ cell Nyquist line, if at all.

These results are of relevence to tests which seek to use flickering targets to measure $\mathrm{M}$ cell function. Our data indicate that for stimuli which flicker at frequencies of $10 \mathrm{~Hz}$ and below, the response is mediated exclusively by $\mathrm{P}$ cells. Even above this temporal frequency there is considerable $\mathrm{P}$ cell stimulation. This means that although $\mathrm{M}$ and $\mathrm{P}$ cells may represent 'parallel pathways' anatomically, there is considerable overlap functionally between these two classes of cells at this eccentricity. Further research is required to examine the effects of changing temporal frequency and contrast on resolution at other retinal eccentricities.

\section{Acknowledgements}

This research is supported by the Ross Foundation and by a Research Fellowship from the Royal National Institute for the Blind.

\section{References}

1. Doesschate, T. (1946) Visual acuity and distribution of percipient elements on the retina. Ophthalmologica, 112 , $1-18$.

2. Weymouth, F. W. (1958) Visual sensory units and the minimal angle of resolution. Am. J. Ophthalmol. 46, 102-113.

3. Anderson, S. J. and Mullen, K. T. and Hess, R. F. (1991) Human peripheral spatial resolution for achromatic and chromatic stimuli: limits imposed by optical and retinal factors. J. Physiol. 442, 47-64.

4. Thibos, L. N., Cheney, F. E. and Walsh, D. J. (1987) Retinal limits to the detection and resolution of gratings. J. Opt. Soc. Am. 4, 1524-1529.

5. Curcio, C. A. and Allen, K. A. (1990) Topography of ganglion cells in human retina. J. Comp. Neurol. 300, 5-25.

6. Williams, D. R. (1985) Aliasing in human foveal vision. Vision Res. 25, 195-205.

7. Williams, D. R. (1985) Visibility of interference fringes near the resolution limit. J. Opt. Soc. Am. A2, 1087-1093.

8. Smith, R. A. and Cass, R. A. (1987) Aliasing in the parafovea with incoherent light. J. Opt. Soc. Am. A4, 15301534.

9. Thibos, L. N., Walsh, D. J. and Cheney, F. E. (1987) Vision beyond the resolution limit: aliasing in the periphery. Vision Res. 27, 2193-2197.

10. Anderson, R. S., Wilkinson, M. O. and Thibos, L. N. (1992) Psychophysical localization of the human visual streak. Optom. Vis. Sci. 69, 171-174.

11. Rovamo, J., Virsu, V., Laurinen, P. and Hyvarinen, L. (1982) Resolution of gratings oriented along and across meridians in peripheral vision. Invest. Ophthalmol. Vis. Sci. 23, 666-670.

12. Dacey, D. M. (1993) The mosaic of midget ganglion cells in the human retina. J. Neurosci. 13, 5334-5355.

13. Schiller, P. H., Charles, E. R. and Logothetis, N. K.(1990) Role of the color-opponent and broad-band channels in vision. Vis. Neurosci. 5, 321-346.

14. Merigan, W. H. and Maunsell, J. H. (1990) macaque vision after magnocellular lateral geniculate lesions. Vis. Neurosci. 5, 347-352. 